\title{
The low-temperature catalyzed etching of gallium arsenide with hydrogen chloride
}

\author{
Jeffrey L. Dupuie and Erdogan Gulari \\ Department of Chemical Engineering, The University of Michigan, Ann Arbor, Michigan 48109
}

(Received 18 September 1991; accepted for publication 10 January 1992)

\begin{abstract}
A heated tungsten filament has been used to catalyze the gas phase etching of gallium arsenide with hydrogen chloride at a substrate temperature of $563 \mathrm{~K}$. Rapid etch rates, between 1 and 3 microns per minute, were obtained in a pure hydrogen chloride ambient in the pressure range of 3.3 to 20.0 Pascal. Low flow rates of hydrogen quenched the etching reaction, and resulted in degradation of the quality of the etched gallium arsenide surface.

Dilution of the hydrogen chloride to $10.5 \%$ in helium reduced the etch rate to 63 nanometers per minute. The removal of $83 \mathrm{~nm}$ of gallium arsenide with the helium-diluted gas mixture resulted in a specular surface. X-ray photoelectron spectroscopy indicated that the gallium arsenide surface became enriched in gallium after the etch in helium-diluted hydrogen chloride. No tungsten or other metal contamination on the etched gallium arsenide surface was detected by x-ray photoelectron spectroscopy.
\end{abstract}

\section{BACKGROUND}

Development of a dielectric deposition scheme for the fabrication of viable gallium arsenide metal-insulatorsemiconductor devices will probably include an in situ surface pretrcatment prior to diclectric deposition due to a high density of semiconductor surface states. These surface states effectively pin the Fermi level of gallium arsenide near midgap. A promising pretreatment for such a deposition scheme is exposure of the gallium arsenide surface to hydrogen chloride, which has been shown to reduce the surface state density and weaken Fermi level pinning. ${ }^{1}$

Hydrogen chloride has been shown to be effective in removing oxygen and carbon contamination from the surface of gallium arsenide prior to homocpitaxial growth by molecular beam epitaxy $(\mathrm{MBE})^{2}$ and metal-organic molecular beam epitaxy (MOMBE). ${ }^{3}$ Oxide free surfaces have been prepared by room-temperature exposure of gallium arsenide to hydrogen chloride vapor at pressures greater than $13 \mathrm{~Pa}^{2}$ However, carbon contamination at the epitaxial layer interface increased by a factor of four with the hydrogen chloride exposure. Despite this contamination, the epitaxial gallium arsenide layer exhibited oval defect densities a factor of five lower than the level of defect densities obtained with regular substrate preparation. Hydrogen chloride gas phase etching of gallium arsenide at temperatures in the range of 720 to $920 \mathrm{~K}$ prior to homoepitaxial gallium arsenide via MOMBE has also resulted in improved epitaxial layer properties. ${ }^{3}$ Smooth substrate surfaces were reported for substrates etched to 25 $\mathrm{nm}$; no surface morphological results were reported for deeper etches. Substrates prepared by cleaning in hydrogen/hydrogen chloride mixtures exhibited improved interfacial carrier concentrations, with interfacial carbon concentrations reduced by an order of magnitude compared to thermal etching. Improved carrier concentrations have also been achieved for gallium arsenide epitaxial growth by MBE through the use of a hydrogen radical pretreatment created by an electron cyclotron resonance (ECR) microwave plasma. ${ }^{4}$
We reported previously that high purity aluminum nitride and silicon nitride films could be deposited by lowpressure chemical vapor deposition (LPCVD) at low substrate temperatures through the catalytic action of a heated filament. ${ }^{5,6}$ In this process, a heated tungsten filament is used to decompose ammonia. Products from the decomposition of ammonia react with either a group III or group IV precursor to form the nitride film. Deposition rates in excess of $200 \mathrm{~nm} / \mathrm{min}$ have been achieved without a plasma, and the resultant film quality compares favorably to nitride deposited with ECR microwave discharges. ${ }^{7-9}$ To further the investigation of the use of films deposited by catalyzed LPCVD as passivation layers and dielectrics for III-V compound semiconductors, a hydrogen chloride gas feed has been added to the reactor system. The hydrogen chloride gas feed will allow the exploration of various gallium arsenide surface pretreatments prior to dielectric film growth. In this paper, results are presented for the etching of gallium arsenide through the decomposition of hydrogen chloride by a heated tungsten filament. This initial study focuses on the effects of the reactor pressure, the diluent gas type, and the diluent gas flow rate on the gallium arsenide etch rate and surface morphology.

\section{EXPERIMENT}

The combined chemical vapor deposition and etching system consists of a six inch diameter, six way stainlesssteel cross reactor, and has been described in detail previously. ${ }^{5,6}$ Semi-insulating (100) gallium arsenide wafers were pressed by molybdenum clamps against an oxidized silicon wafer which was in turn clamped against a stainless-steel susceptor. The susceptor was heated by two $300 \mathrm{~W}$ cartridge heaters. A sheathed type $K$ thermocouple inserted into a thermowell drilled near the surface of the susceptor was used to monitor the susceptor temperature. The wafer temperature was calibrated under reaction conditions with a type $C$ thermocouple clamped to the surface of the wafer. The tungsten filament temperature was measured with a pyrometer, and was set to $2020 \mathrm{~K}$. To confirm 


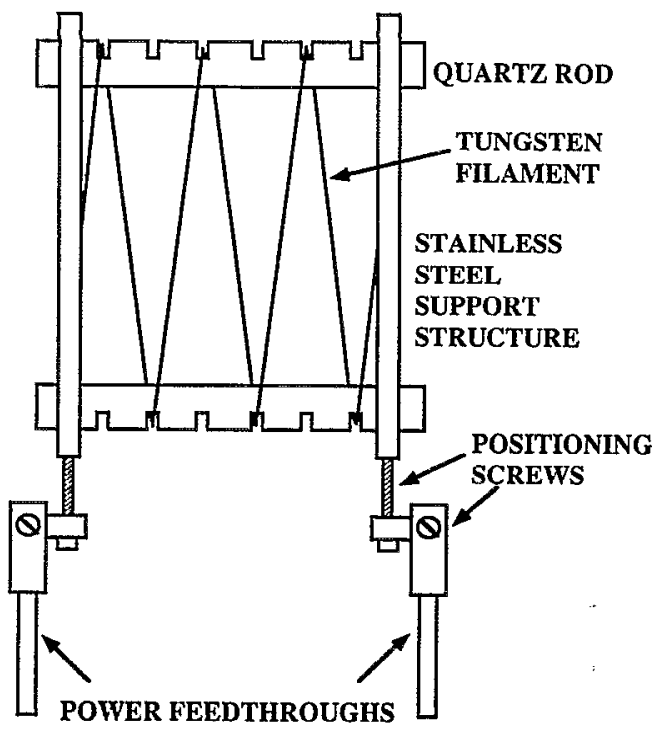

FIG. 1. Heated tungsten filament unit.

the pyrometer readings, the average tungsten filament resistivity was measured and gave results which confirmed the pyrometer measurements to within $50 \mathrm{~K}$.

The tungsten filament unit consisted of $93 \mathrm{~cm}$ of 0.25 $\mathrm{mm}$ diameter tungsten wire wrapped around $13 \mathrm{~mm}$ diameter quartz support rods, as depicted in Fig. 1. The quartz rods were notched to evenly distribute the wound filament. Additional notches in the quartz rods and the stainlesssteel supports allowed flexible assembly of the tungsten filament unit. Stainless-steel sleeves provided connections to the power feedthroughs. The position of the tungsten filament unit could be adjusted by positioning screws. As in previous thin nitride film depositions, the unit was located $4 \mathrm{~cm}$ from the wafer surface.

The gallium arsenide was maskcd with a sputtered film of silicon dioxide $140 \mathrm{~nm}$ thick. The silicon dioxide was patterned by conventional ultraviolet lithography followed by wet etching in a buffered hydrofluoric acid solution. Prior to etching in hydrogen chloride, the substrates were degreased in the solvent sequence trichloroethane, acetone, and methanol. After a rinse in deionized water, the gallium arsenide surface oxide layer was etched in a 1:1 solution of hydrochloric acid (37\%) in deionized water. The substrates were then dried in nitrogen and loaded immediately into the reactor. The gases employed for etching were $99.999 \%$ helium, $99.999 \%$ hydrogen, and $99.997 \%$ hydrogen chloride. The gallium arsenide etched feature depths were measured with a scanning profilometer.

\section{RESULTS AND DISCUSSIONS}

Table I lists the etch rate of gallium arsenide as a function of the reactor pressure for a pure hydrogen chloride feed of $19.2 \mathrm{sccm}$ at a temperature of $563 \mathrm{~K}$. The run to run variation in the etch rates was typically limited to less than ten percent. The etch rate experienced a maximum at 6.7 $\mathrm{Pa}$. The etch rate is expected to be dependent on the flux of chlorine atoms to the gallium arsenide sur-
TABLE I. Reactor etching parameters and etch rates for the catalyzed gas phase etching of gallium arsenide with hydrogen chloride.

\begin{tabular}{ccccccc}
\hline \hline Sample & $\begin{array}{c}\text { Substrate } \\
\text { temp. (K) }\end{array}$ & $\begin{array}{c}\text { Pressure } \\
(\mathrm{Pa})\end{array}$ & $\begin{array}{c}\mathrm{HCl} \text { flow } \\
\text { (sccm) }\end{array}$ & $\begin{array}{c}\mathrm{H}_{2} \text { flow } \\
(\mathrm{sccm})\end{array}$ & $\begin{array}{c}\text { He flow } \\
(\mathrm{sccm})\end{array}$ & $\begin{array}{c}\text { Etch rate } \\
(\mathrm{nm} / \mathrm{min})\end{array}$ \\
\hline $4 G$ & 563 & 20 & 19.2 & 0 & 0 & 1820 \\
$4 F$ & 563 & 6.7 & 19.2 & 0 & 0 & 3060 \\
$5 F$ & 563 & 3.3 & 12.7 & 0 & 0 & 1720 \\
$4 L$ & 563 & 6.7 & 19.2 & 4.3 & 0 & 630 \\
$5 B$ & 563 & 6.7 & 19.2 & 10.4 & 0 & 0 \\
$5 C$ & 563 & 6.7 & 4.3 & 0 & 36.5 & 63 \\
\hline \hline
\end{tabular}

face. Analogous to the decomposition of other molecules on hot filaments, ${ }^{10}$ the low-pressure hydrogen chloride decomposition rate to form chloride atoms may be linearly proportional to the hydrogen chloride pressure at the high filament temperatures used in this study. At higher reactor pressures, however, radical recombination in the gas phase can be expected to lower the flux of chlorine atoms arriving at the gallium arsenide surface. Thus, the gallium arsenide etch rate can be expected to exhibit a maximum with respect to the reactor pressure. The feed rate of hydrogen chloride was limited to $12.7 \mathrm{sccm}$ at $3.3 \mathrm{~Pa}$ due to the lower pumping speed of the vacuum pump at low reactor pressures. Calculations based upon the assumption of fully chlorinated reaction products indicated that less than five percent of the hydrogen chloride was consumed by the etching reaction, so the decreased feed rate at $3.3 \mathrm{~Pa}$ should not appreciably affect the gallium arsenide etch rate. The extremely rapid etch rates of 1 and $3 \mu \mathrm{m} / \mathrm{min}$ are comparable to those reported for hot jet gas etching of gallium arsenide with chlorine. ${ }^{11,12}$

Figure 2 shows the surface morphology and the isotopic nature of the etched gallium arsenide surface at a reactor pressure of 6.7 $\mathrm{Pa}$. Under no conditions was anisotropic etching observed, as has been reported for downstream ECR microwave plasma chlorine radical etching. ${ }^{13}$ Brief etches, less than 1 min, under these conditions yielded smooth surfaces as determined by Nomarski and visual inspection, but scanning electron microscope (SEM) photographs showed a surface morphology comparable to Fig. 2. The surface of gallium arsenide etched at 3.3 Pa exhibited similar characteristics to those shown in Fig. 2. Figure 3 shows the surface morphology obtained at a reactor pressure of $20 \mathrm{~Pa}$. Facets roughly triangular in shape were observed for etches at pressures higher than 6.7 Pa.

Hydrogen was added to the gas mixture to decrease the gallium arsenide etch rate to a more controllable value for surface pretreatment prior to dielectric deposition. The etch rate dependence on the hydrogen flow rate is listed in Table I. Low flow rates of hydrogen significantly reduced the etch rate. The etch of gallium arsenide was completely quenched upon the addition of $10.4 \mathrm{sccm}$ of hydrogen. The addition of hydrogen resulted in the degradation of the etched gallium arsenide surface morphology, as shown in Fig. 4. This morphology is very similar to the rough surface morphology reported previously, ${ }^{14}$ and observed in our laboratory for the thermal reaction of hydrogen chlo- 

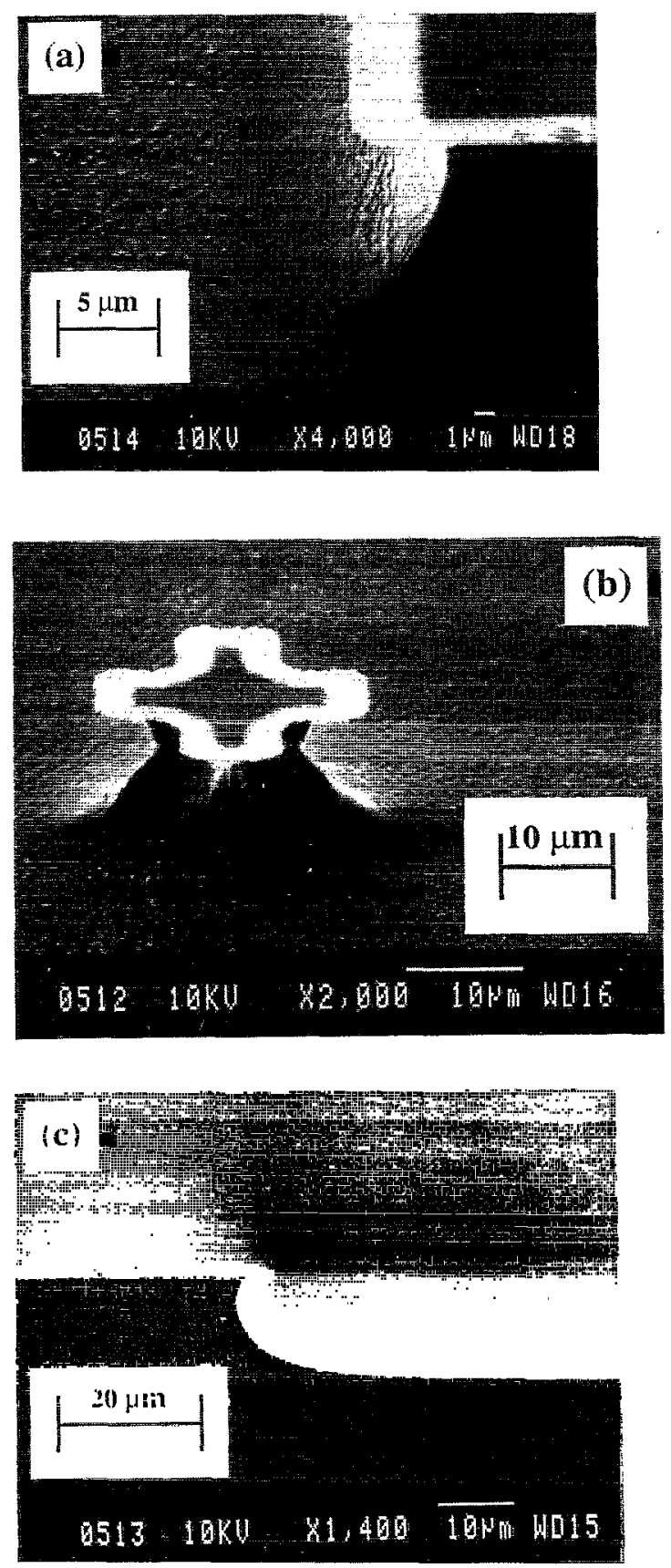

FIG. 2. Hot filament catalyzed gallium arsenide etched surface. $\mathrm{HCl}$ flow $=19.2 \mathrm{secm}$, pressure $=6.7 \mathrm{~Pa}$, substrate temperature $=563 \mathrm{~K} \mathrm{(a)} \mathrm{and}$ (b) surface morphology, $60^{\circ}$ from surface normal. (c) $90^{\circ}$ from normal. Note the isotropic nature of the catalyzed etch.

ride with gallium arsenide at higher temperalures ( 750 to $920 \mathrm{~K}$ ). These results indicate a possible similarity in the etching mechanism between these two techniques, and also indicate that atomic or molecular hydrogen may induce surface roughness for gas phase chlorine-based gallium arsenide etches.

The etched gallium arsenide surface morphology is expected to depend on the etching mechanism. Mass spectroscopy investigations of the kinetic and products of pure chlorine etching of gallium arsenide have yielded conflict-

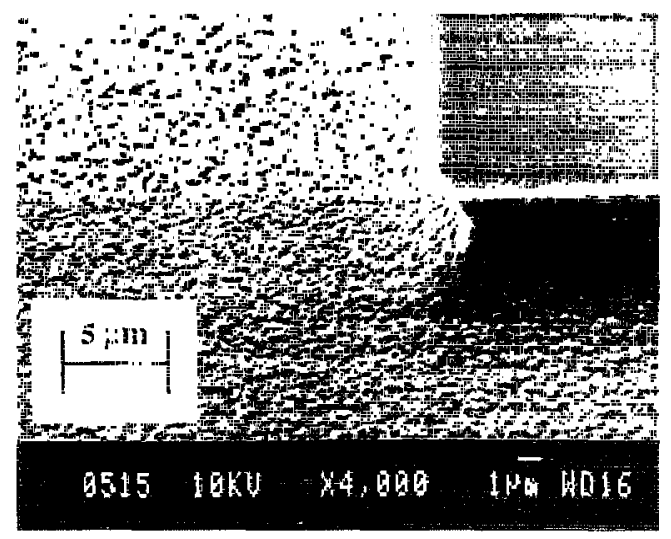

FIG. 3. Hot filament catalyzed gallium arsenide etched surface. $\mathrm{HCl}$ flow $=19.2 \mathrm{sccm}$, pressure $=20 \mathrm{~Pa}$, substrate temperature $=563 \mathrm{~K}$. Note the triangular shaped facets.

ing results. ${ }^{15,16}$ At the temperature used in this study, the major gas phase products from gallium arsenide etching were $\mathrm{As}_{4}$ for a five percent mixture of chlorine in helium at $10^{-4} \mathrm{~Pa}^{15}$ and $\mathrm{AsCl}$ for pure chlorinc gas at $3 \times 10^{-2}$ $\mathrm{Pa} .{ }^{16}$ Temperature programed desorption studies of a GaAs surface exposed to atomic hydrogen, created by a hot tungsten ribbon, have revealed that both hydrogen and arsine desorbed under appropriate atomic hydrogen exposures. ${ }^{17}$ No gallium hydride species were observed to desorb, indicating that changes in the GaAs surface stoichiometry could occur with atomic hydrogen exposure. Hydrogen desorption occurred at temperatures up to approximately $660 \mathrm{~K}$. Under the conditions employed in this work, atomic hydrogen may exhibit a pressure dependent interaction with surface arsenic sites to prevent the formation of volatile arsenic chlorides, and thus alter the reaction mechanism and the surface morphology. The rapid atentuation of the etch rate with increased hydrogen flow suggests that homogeneous or heterogeneous radical recombination, or the preferential adsorption and reaction of hydrogen on the heated filament limit the etching process.

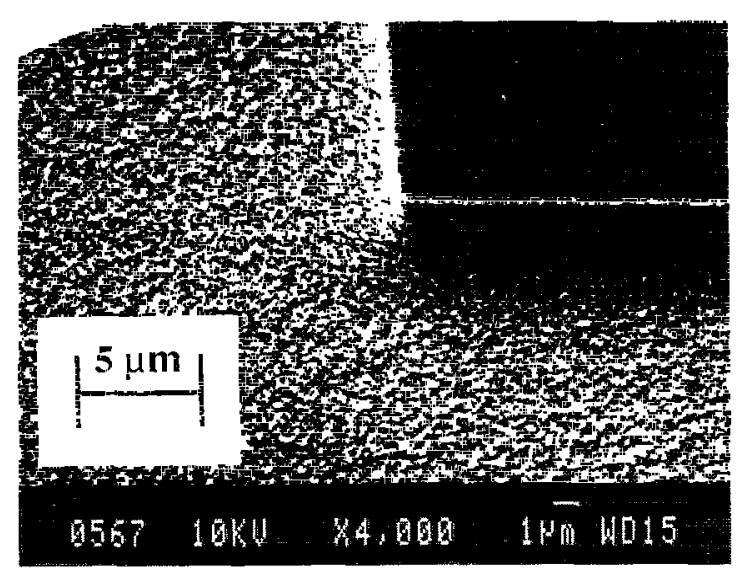

FIG. 4. Hot filament catalyzed gallium arsenide etched surface morphology with hydrogen dilution. $\mathrm{H}_{2}$ flow $=4.3 \mathrm{sccm}$, $\mathrm{HCl}$ flow $=19.2 \mathrm{sccm}$, pressure $=6.7 \mathrm{~Pa}$, substrate temperature $=563 \mathrm{~K}$. 


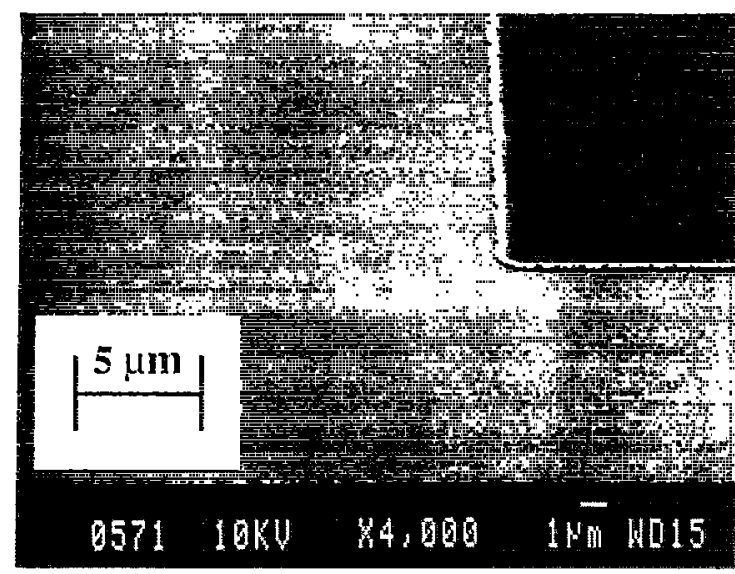

FIG. 5. Hot filament catalyzed gallium arsenide etched surface mrophology with helium dilution. He flow $=36.5 \mathrm{sccm}, \mathrm{HCl}$ flow $=4.3 \mathrm{sccm}$, pressure $=6.7 \mathrm{~Pa}$, substrate temperature $=563 \mathrm{~K}$.

The unsuitability of hydrogen as a diluent for the catalyzed gallium arsenide etching process prompted the investigation of helium as an inert gas diluent to assist in reducing the galluim arsenide etch rate. Figure 5 shows the gallium arsenide surface after the removal of $83 \mathrm{~nm}$ for a mixture of $10.5 \% \mathrm{HCl}$ in helium at a flow rate of $40.8 \mathrm{sccm}$ and a reactor pressure of $6.7 \mathrm{~Pa}$. The etch rate under these conditions was $63 \mathrm{~nm} / \mathrm{min}$. The gallium arsenide surface under these conditions appeared smooth under visual, Nomarski, and SEM inspection. Higher magnification SEM inspection of the surface revealed a slight surface texture that could not be resolved. Etches for longer times ( $>5 \mathrm{~min}$ ) under these conditions resulted in moderate roughening of the gallium arsenide surface, with the appearance of hemispherical features possessing a characteristic lateral dimension of $100 \mathrm{~nm}$.

The surface composition of the etched surface illustrated in Fig. 5 was investigated by $\mathrm{x}$-ray photoelectron spectroscopy (XPS). No contamination from the reactor wetted materials iron, copper, molybdenum, and tungsten was observed. Also absent from the etched surface was chlorine. The gallium arsenide surface was oxidized and exhibited carbon contamination, as is expected for sample transfer from the reactor chamber to the spectrometer chamber. XPS indicated that the surface had become enriched in gallium, as was predicted for atomic hydrogen exposure. ${ }^{17}$ The measured gallium to arsenic ratio was determined to be 1.3 from integration of the area of the gallium $2 p_{3}$ and arsenic $3 d$ photoelectron peaks.

Substantial tungsten contamination of the gallium arsenide surface was not expected based upon the results of a mass spectrometric study of the kinetics of the etching of tungsten with chlorine and atomic chlorine. ${ }^{18}$ The formation of volatile tungsten chlorides from the reaction of tungsten with chlorine is expected to occur only at lower temperatures ( $<1000 \mathrm{~K})$ through an Eley-Rideal mechanism involving gas phase molecular chlorine or atomic chlorine. The use of hydrogen chloride precludes a mechanism involving molecular chlorine, although etching of tungsten with hydrogen chloride through a different mechanism is a possibility. No measurable change in the resistance of the tungsten filament was observed during the course of several runs, indicating minimal attack by hydrogen chloride on the filament. We might expect, however, a small tungsten contamination of the gallium arsenide surface not measurable by XPS from a reaction mechanism involving atomic chlorine attack on the cooler portion of the heated filament in contact with the cooler tungsten filament unit supporting rods.

\section{SUMMARY}

A hot tungsten filament has been shown to effectively catalyze the etching of gallium arsenide at a substrate temperature of $563 \mathrm{~K}$ through the dissociation of hydrogen chloride. Rapid etch rates between 1 and $3 \mu \mathrm{m} / \mathrm{min}$ were obtained in a pure hydrogen chloride ambient. The addition of small flow rates of hydrogen quenched the etching reaction and contributed to degradation in the galium arsenide surface morphology. Diluting the hydrogen chloride in helium resulted in more feasible etch rates for gallium arsenide pretreatment prior to dielectric deposition, and also resulted in specular etched galium arsenide surfaces for short etching times. The hot filament enhanced gallium arsenide etching method might provide a feasible gallium arsenide surface cleaning step prior to dielectric film deposition. Thin nitride film depositions can be performed immediately subsequent to the cleaning/etching procedure merely by gas feed switching from the etching gas mixture to the film growth gases.

${ }^{1}$ H. Hasegawa, H. Ishii, T. Sawada, T. Saitoh, S. Konishi, Y. Lui, and H. Ohno, J. Vac. Sci. Technol. B 6, 1184 (1988).

${ }^{2}$ J. P. Contour, H. Massies, A. Saletes, M. Outrequin, F. Simondet, and

J. F. Rochette, J. Vac. Sci. Technol. B 5, 730 (1987).

${ }^{3}$ J. Saito, K. Nanbu, T. Ishikawa, and K. Kondo, J. Cryst. Growth 95, 322 (1989).

${ }^{4}$ S. Sugata, A. Takamori, N. Takado, K. Asakawa, E. Miyauchi, and H. Hashimoto, J. Vac. Sci. Technol. B 5, 1087 (1988).

${ }^{5}$ J. L. Dupuie, F. Terry, and E. Gulari (unpublished).

${ }^{6} J$. L. Dupuie, F. Terry, and E. Gulari (unpublished).

${ }^{7}$ H. Nomura, H. Nomura, Y. Nakanishi, and Y. Hatanaka, J. Appl. Phys. 69, 990 (1991).

${ }^{8}$ S. Meikle, S. Meikle, Y. Nakanishi, and Y. Hatanaka, J. Appl. Phys. 67, 483 (1990).

${ }^{9}$ S. V. Nguyen and K. Albaugh, J. Electrochem. Soc. 136, 2835 (1989).

${ }^{10}$ See, for example, M. Grosman, and D. G. Loffler, J. Catal. 80, 188 (1983).

${ }^{11}$ M. W. Geis, N. N. Efremow, and G. A. Lincoln, J. Vac. Sci. Technol. B 4, 315 (1986).

${ }^{12}$ M. W. Geis, N. N. Efremow, S. W. Pang, and A. C. Anderson, J. Vac. Sci. Technol. B 5, 363 (1987).

${ }^{13}$ S. Sugata and K. Asakawa, J. Vac. Sci. Technol. B 5, 894 (1987).

${ }^{14}$ S. Dorshchand, L. Daweritz, and H. Berger, Crystal Res. \& Technol. 18, 1359 (1983).

${ }^{15}$ H. Hou, Z. Zhang, S. Chen, C. Su, W. Yan, and M. Vernon, Appl. Phys. Lett. 55, 801 (1989).

${ }^{16}$ M. Balooch, D. R. Olander, and W. J. Siekhaus, J. Vac. Sci. Technol. B 4, 794 (1986).

${ }^{17}$ J. R. Creighton, J. Vac. Sci. Technol. A 8, 3984 (1990).

${ }^{18}$ M. Balooch, D. S. Fischl, D. R. Olander, and W. J. Siekhaus, J. Electrochem. Soc. 135, 2090 (1988). 